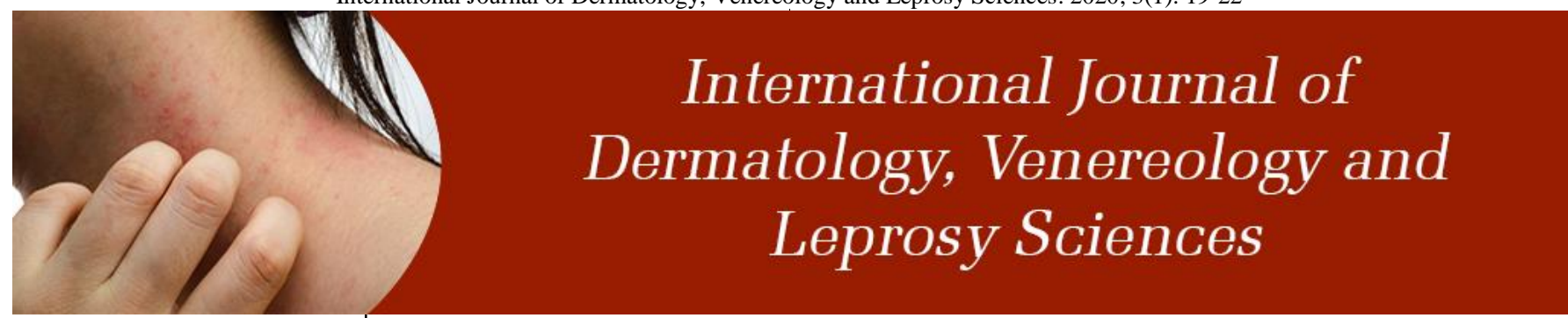

E-ISSN: 2664-942X

P-ISSN: 2664-9411

www.dermatologypaper.com

Derma 2020; 3(1): 19-22

Received: 09-11-2019

Accepted: 11-12-2019

Dr. Priyanka Reddy R

Senior Resident, Department of Dermatology, Vydehi

Institute of Medical sciences and Research Centre,

Bengaluru, India

Dr. Priyatharshini V Junior Resident, Department of Dermatology, Aarupadai Veedu Medical College and Hospital, Pondicherry, India

Dr. Hanumanthayya K Professor and HOD, MD Dermatology, Vydehi Institute of Medical Sciences and Research Centre, Bengaluru, India
Corresponding Author: Dr. Priyanka Reddy R Senior Resident, Department of Dermatology, Vydehi Institute of Medical sciences and Research Centre, Bengaluru, India

\section{A study on correlates of acute cutaneous manifestations in head and neck cancer patients treated with radiation therapy}

\author{
Dr. Priyanka Reddy R, Dr. Priyatharshini V and Dr. Hanumanthayya K
}

DOI: https://doi.org/10.33545/26649411.2020.v3.i1a.33

\begin{abstract}
Skin injuries occur in about $95 \%$ of patients who receive RT. Anybody site treated with RT is susceptible to cutaneous injury; however, the face, neck, trunk, and extremities are particularly vulnerable. Patients with breast cancer, head and neck cancer, lung cancer, and sarcoma are most often affected because of the higher radiation doses to the skin. RT was formerly used by dermatologists in the treatment of benign conditions such as acne, eczema and psoriasis. Patients receiving radiation therapy for Head and Neck malignancies attending the outpatient clinic in Department of Dermatology, Venereology and Leprosy and Radiotherapy and also inpatients in Radiotherapy wards were included in this study. The most common co-morbidity observed in this study was anemia in 39 patients (78\%), followed by diabetes mellitus in 6 patients $(12 \%)$ followed by hypertension in 3 patients $(6 \%)$, both hypertension and diabetes mellitus was seen in 1 patient $(2 \%)$ and hypertension, diabetes mellitus and IHD was seen in 1 patient (2\%).
\end{abstract}

Keywords: correlates, acute cutaneous manifestations, radiation therapy

\section{Introduction}

Prior to the advent of ionizing particle beams, medicine had few options for treating some malignant and benign diseases. Physicians 'needs for new techniques to address these problems formed a vacuum, clearly demonstrated immediately following the discovery of Xrays in November $1895^{[1]}$

Radiation medicine developed over four major eras: the era of discovery, from Rontgen's discovery to about the late 1920s; the orthovoltage era, from the late 1920s through World War II; the megavoltage era, which began with higher-energy linacs for therapy in the 1950s, and, with refinements such as intensity-modulated X-ray therapy (IMXT), is still ongoing.

Skin injuries occur in about $95 \%$ of patients who receive RT. Any body site treated with RT is susceptible to cutaneous injury; however, the face, neck, trunk, and extremities are particularly vulnerable. Patients with breast cancer, head and neck cancer, lung cancer, and sarcoma are most often affected because of the higher radiation doses to the skin. RT was formerly used by dermatologists in the treatment of benign conditions such as acne, eczema and psoriasis ${ }^{[2]}$.

The overall incidence of acute erythematous reactions is $80-90 \%$, while moist desquamation is seen in around $10-15 \%$ of the patients undergoing RT to radical doses.

Majority of patients undergoing radiotherapy for head and neck cancers experience mild to moderate (grade 1-2) radiation dermatitis, while about $25 \%$ patients experience severe toxicity (grade 3 ).

The main function of skin is to establish an effective physical and immunological barrier against the surrounding environment. Skin is susceptible to radiation damage because it is a continuously renewing organ containing rapidly proliferating and maturing cells. The basal keratinocytes, hair follicle stem cells, and melanocytes are highly radiosensitive. Radiation skin injury involves immediate damage to basal keratinocytes and hair follicle stem cells, followed by a burst of free radicals, irreversible double-stranded breaks in nuclear and mitochondrial DNA and inflammation. During radiation therapy, the first fractionated dose of radiation destroys a percentage of basal keratinocytes, resulting in a disruption of the selfrenewing property of epidermis. These repeated exposures do not allow time for cells to repair tissue or DNA damage. Although the remaining keratinocytes are stimulated to 
proliferate, these cells are continually destroyed with each fractionated radiation treatment ${ }^{[3]}$. Since skin is a continuously renewing organ, and radiotherapy not only interferes with normal maturation, reproduction and repopulation of germinative epidermal and hair matrix cells, but also targets fibroblasts and the cutaneous vasculature. The radiation induced injury has been termed a - complex woundll, in which structural tissue damage occurs instantaneously, mediated by a burst of free radicals resulting in DNA damage and alteration of proteins, lipids and carbohydrates. Each additional exposure or fraction contributes to inflammatory cells recruitment as well as to direct tissue injury. Wound healing is further impaired by inhibition of normal granulation tissue, fibrogenesis and angiogenesis. Acute injury is, therefore, a consequence of reduction and impairment of functional stem cells, endothelial cell changes, inflammation and epidermal cell apoptosis and necrosis. Areas of the body that contain skin folds, such as the groin, are at a higher risk of developing a reaction because of a phenomenon called the - bolus effect; these areas are more likely to receive a higher dose of radiation and more prone to bacterial contamination. Prescribed treatment at low doses $(<2000$ cGy $)$ in conventional fractionation at depth usually does not elicit a skin reaction, and consequently, patients receiving palliative treatment are not usually at risk ${ }^{[4,5]}$.

Also the functional subunit (FSU) of skin is a single microvessel with associated epidermis and dermis. Radiation exposure causes depletion of basal epithelial layers of skin. It also induces an inflammatory and a vascular response with extracapillary cell injury and capillary dilation. Pigmentary changes are caused by increased melanin production by melanocytes and the migration of melanin to the more superficial layers of the epidermis. The exposure of the subdermal lymphatics as a result of loss of the superficial epithelium leads to moist desquamation, or after higher doses, skin necrosis. Similar damage caused to the epithelial lining of hair follicles, causes epilation. Telangiectasia result from excessive loss of microvascular endothelium, causing capillary loops to contract and fuse into dilated channels beneath an atrophied epidermis ${ }^{[6]}$.

EGFR is expressed in the basal layer of the epidermis, and is known to be essential to the regulation of several aspects of normal keratinocyte biology. Effects of EGFR inhibition include impaired growth and migration of keratinocytes and inflammatory chemokine expression by these cells. These effects lead to inflammatory cell recruitment and subsequent cutaneous injury, which accounts for the majority of symptoms, including acneiform rash, xerosis, pruritus, hyperpigmentation, fissures in fingers and toes, hypertrichosis, periungual inflammation and onycholisis. The acneiform rash appears in those areas rich of sebaceous glands such as face, neck, retroauricular area, back, upper trunk, and the scalp. The most common clinical symptoms associated are: confluent pustules, diffuse erythema with telangiectasias or papulopustules, seborrheic dermatitis-like rash, edematous facial erythema. Histologic specimens reveal a mixed inflammatory infiltrate surrounding the upper areas of the dermis, follicular rupture, and epithelial acantholysis ${ }^{[7,8]}$.

\section{Methodology}

Patients receiving radiation therapy for Head and Neck malignancies attending the outpatient clinic in Department of Dermatology, Venereology and Leprosy and Radiotherapy and also inpatients in Radiotherapy wards were included in this study.

\section{Inclusion Criteria}

- Patients of both genders of all age groups who are receiving/have received radiotherapy for head and neck cancer sites.

- Patients treated with definitive radiation therapy.

- Patients willing to give informed written consent.

\section{Exclusion Criteria}

- Patients having any primary dermatosis.

- Patients with skin manifestations due to other systemic diseases prior to radiotherapy.

- $\quad$ Patients treated with palliative intent.

\section{Statistical Analysis}

Type of study: Observational study

Analysis of data: Demographically was presented using percentage/proportion. The prevalence of frequency of occurring manifestations will be presented using percentage/proportion.

Association with radiotherapy dose and risk factors was analysed using chi square test and $\mathrm{p}$ value was calculated.

\section{Results}

In this study the age range of patients was 4-74 years, mean age being 49.96. The maximum number of patients, 14 (28\%) were in age group 51-60 followed by 11 patients (22\%) in 41-50 group. 10 patients (20\%) were in age group $61-70$ and 6 patients (10\%) in 31-40 group. Only 2 patients $(4 \%)$ below the age of 20 years were present.

Among 50 patients, $29(58 \%)$ were males and $21(42 \%)$ were females with a male to female ratio of 1.38:1.

Most of the patients had an ECOG performance status of grade 1 seen in 47 patients (94\%) while grade 2 was seen in 3 patients $6 \%$.

The most common co-morbidity observed in this study was anemia in 39 patients (78\%), followed by diabetes mellitus in 6 patients $(12 \%)$ followed by hypertension in 3 patients (6\%), both hypertension and diabetes mellitus was seen in 1 patient $(2 \%)$ and hypertension, diabetes mellitus and IHD was seen in 1 patient $(2 \%)$.

Tables 1: Age distribution of patients

\begin{tabular}{|c|c|c|}
\hline Age & Frequency & Percent \\
\hline$\leq 20$ & 2 & 4.0 \\
\hline $21-30$ & 5 & 10.0 \\
\hline $31-40$ & 6 & 12.0 \\
\hline $41-50$ & 11 & 22.0 \\
\hline $51-60$ & 14 & 28.0 \\
\hline $61-70$ & 10 & 20.0 \\
\hline $71-80$ & 2 & 4.0 \\
\hline total & 50 & 100.0 \\
\hline
\end{tabular}

Table 2: Gender distribution of patients

\begin{tabular}{|c|c|c|}
\hline sex & Frequency & Percent \\
\hline Female & 21 & 42.0 \\
\hline Male & 29 & 58.0 \\
\hline Total & 50 & 100.0 \\
\hline
\end{tabular}


Table 3: ECOG Performance Status of Patients

\begin{tabular}{|c|c|c|}
\hline ECOG Performance & Frequency & Percent \\
\hline Grade-1 & 47 & 94.0 \\
\hline Grade- 2 & 3 & 6.0 \\
\hline Total & 50 & 100.0 \\
\hline
\end{tabular}

Table 4: Co-morbidities

\begin{tabular}{|c|c|c|}
\hline Co-morbidities & Frequency & Percent \\
\hline Diabetes & 6 & 12.0 \\
\hline Diabetes and Hypertension & 1 & 2.0 \\
\hline Diabetes, Hypertension \& IHD & 1 & 2.0 \\
\hline Hypertension & 3 & 6.0 \\
\hline Anemia & 39 & 78.0 \\
\hline Total & 50 & 100.0 \\
\hline
\end{tabular}

Table 5: Radiation

\begin{tabular}{|c|c|c|}
\hline Radiation & Frequency & Percent \\
\hline Definitive & 19 & 38.0 \\
\hline Adjuvant & 31 & 62.0 \\
\hline Total & 50 & 100.0 \\
\hline
\end{tabular}

Tables 6: Dose Per Fraction

\begin{tabular}{|c|c|c|c|c|c|c|}
\hline \multirow{3}{*}{$\begin{array}{l}\text { Dose Per } \\
\text { Fraction } \\
\end{array}$} & & & \multicolumn{4}{|c|}{ Skin } \\
\hline & \multicolumn{2}{|c|}{ Grade-1 } & \multicolumn{2}{|c|}{ Grade-2 } & \multicolumn{2}{|c|}{\begin{tabular}{|l} 
Grade-3 \\
\end{tabular}} \\
\hline & Count & $\%$ & Count & $\%$ & Count & $\%$ \\
\hline 2 & 21 & $87.5 \%$ & 18 & $100.0 \%$ & 8 & $100.0 \%$ \\
\hline 2.1 & 1 & $4.2 \%$ & 0 & $0.0 \%$ & 0 & $0.0 \%$ \\
\hline 3 & 2 & $8.3 \%$ & 0 & $0.0 \%$ & 0 & $0.0 \%$ \\
\hline total & 24 & $100.0 \%$ & 18 & $100.0 \%$ & 8 & $100.0 \%$ \\
\hline
\end{tabular}

Tables 7: Total Dose Delivered

\begin{tabular}{|c|c|c|c|}
\hline \multirow{2}{*}{ Skin } & \multicolumn{3}{|c|}{ Treatment time (no of fractions) } \\
\cline { 2 - 4 } & $\mathbf{N}$ & Mean & Sd \\
\hline Grade-1 & 24 & 23.54 & 7.34 \\
\hline Grade- 2 & 18 & 26.44 & 8.54 \\
\hline Grade-3 & 8 & 30.75 & 3.85 \\
\hline Total & 50 & 25.27 & 7.70 \\
\hline
\end{tabular}

Tables 8: Site of Treatment

\begin{tabular}{|c|c|c|c|c|c|c|}
\hline \multirow{2}{*}{$\begin{array}{c}\text { Site of } \\
\text { Treatment }\end{array}$} & & \multicolumn{4}{|c|}{ Skin } \\
\cline { 2 - 7 } & \multicolumn{2}{|c|}{ Grade-1 } & \multicolumn{2}{c|}{ Grade-2 } & \multicolumn{2}{c|}{ Grade-3 } \\
\hline & Count & \% & Count & \% & Count & \% \\
\hline Head & 16 & $66.7 \%$ & 9 & $50.0 \%$ & 4 & $50.0 \%$ \\
\hline Neck & 8 & $33.3 \%$ & 9 & $50.0 \%$ & 4 & $50.0 \%$ \\
\hline total & 24 & $100.0 \%$ & 18 & $100.0 \%$ & 8 & $100.0 \%$ \\
\hline Chi-square value $=1.42 ; \mathrm{df}=2 ; \mathrm{P}=0.49$ \\
\hline
\end{tabular}

\section{Discussion}

The use of ionizing radiation for the treatment of cancer dates back to the late $19^{\text {th }}$ century, with the discovery of $\mathrm{X}$ rays by Wilhelm Roentgen in 1895 followed by the discovery of natural radioactivity by Henri Becquerel in 1896 and isolation of radium by Marie Curie in 1898. Radiotherapy is now considered the standard of care for locally advanced squamaous cell carcinoma (SCCHN) and for high risk postoperative patients. As the treatment strength increases, so does the risk of toxicity. Dermatologists today are no strangers to these cutaneous adverse reactions and called on to treat the cutaneous repercussions of radiation therapy which is a function of technique, target, total dose, volume, as well as individual variation ${ }^{[9]}$.
In our study, male predominance was noted with 29 (58\%) males and $21(42 \%)$ females out of total 50 patients. Norman's study also showed high male predominance $(80 \%$ males and $20 \%$ females) ${ }^{[10]}$.

Most of the patients in our study received total radiation dose 30-70 Gray with a mean of 58.94 Gy and the dose per fraction received by all patients was in the range of 2-3 Gy with 47 patients $(94 \%)$ receiving $2 \mathrm{~Gy}, 2$ patients $(4 \%)$ received $3 \mathrm{~Gy}$ and 1 patient $(2 \%)$ received $2.1 \mathrm{~Gy}$.

In a study by Krasin et al. the mean dose received was 50.40 Gray ${ }^{[11]}$.

The patient related factors like poor nutritional status, history of severe skin reaction to sun exposure, fair complexion, diabetes, smoking, pre-existing connective tissue or auto immune diseases, burned skin, skin donor site, radiation at skin fold, postoperative radiation and infectious diseases like HIV predisposes patients to radiation dermatitis ${ }^{[12]}$.

The presence of anemia was found to be significantly associated with radiation dermatitis. Among the study population, the most common co-morbidity was anemia in $78 \%$ patients, followed by diabetes mellitus in $12 \%$ patients. Association of other factors with severity of skin changes was not found to be significant.

No other study has shown such association with any of the risk factors mentioned.

\section{Conclusion}

- Among 50 patients, 29 (58\%) were males and 21 (42\%) were females.

- Male to female ratio observed in this study was 1.38:1.

- The age range in our study was $4-74$ years with maximum number of patients, 35

- $\quad(70 \%)$ were in t h e age group of $41-70$ years.

- The most common co-morbidity observed in this study was anemia seen in 39 patients (78\%), followed by diabetes mellitus in 6 patients $(12 \%)$.

\section{References}

1. Toledo-Pereyra LH. X-Rays Surgical Revolution. Journal of Investigative Surgery. 2009; 22(5):327-32.

2. Ryan C. Grenz ray therapy in dermatology. $\mathrm{Br} \mathbf{J}$ Dermatol. 1942; 54:47.

3. Dutreix J. Human skin: early and late reactions in relation to dose and its time distribution. $\mathrm{Br} \mathrm{J}$ Radiol Suppl. 1986; 19:22-8.

4. McQuestion M. Evidence-based skin care management in radiation therapy: clinical update. Semin Oncol Nurs. 2011; 27(2):e1-17.

5. Archambeau JO, Pezner R, Wasserman $\mathrm{T}$. Pathophysiology of irradiated skin and breast. Int $\mathbf{J}$ Radiat Oncol Biol Phys. 1995; 31(5):1171-85.

6. Hickok JT, Morrow GR, Roscoe JA, Mustian K, Okunieff P. Occurrence, severity, and longitudinal course of twelve common symptoms in 1129 consecutive patients during radiotherapy for cancer. $\mathbf{J}$ Pain Symptom Manag. 2005; 30(5):433-42.

7. Porock D, Kristjanson L. Skin reactions during radiotherapy for breast cancer: The use and impact of topical agents and dressings. Eur J Cancer Care (Engl). 1999; 8:143-53.

8. Bonner JA, Harari PM, Giralt J, Azarnia N, Shin DM, Cohen RB, et al. Radiotherapy plus cetuximab for squamous cell carcinoma of the head and neck. N Engl 
J Med. 2006; 354:567-78.

9. Archambeau JO, Shymko RM. Tissue population configuration as a modifier of organ dose response. Int J Radiat Oncol Biol Phys. 1988; 15:727-34.

10. Price NM. Radiation dermatitis following electron beam therapy. Arch Dermatol. 1978; 114: 63-66.

11. Krasin MJ, Hoth KA, Hua C, Gray JM, Wu S, Xiong X. Incidence and Correlates of Radiation Dermatitis in Children and Adolescents Receiving Radiation Therapy for the Treatment of Paediatric Sarcomas. Clinical Oncology. 2009; 21(10):781-85.

12. Conill C, Azon-Masoliver A, Verger E, Lecha V. Pityriasis versicolor confined to the radiation therapy field. Acta Oncol. 1990; 29:949-50. 